\title{
Electrical and Mechanical Properties of Zirconia-Graphene Composites
}

\author{
A.G. Glukharev ${ }^{1,2}$, V.G. Konakov ${ }^{1,2}$ and O.Yu. Kurapova ${ }^{2,3}$ \\ ${ }^{1}$ Institute for Problems in Mechanical Engineering, V.O., Bolshoj pr. 61, St. Petersburg, 199178, Russia \\ ${ }^{2}$ Peter the Great St. Petersburg Polythechnic University, Politechnicheskaya, St. Petersburg, 195251, Russia \\ ${ }^{3}$ Institute of chemistry, St. Peterburg State University, Universitetskaya emb. 7-9, St. Petersburg, 199034, Russia
}

Received: December 15, 2020

\begin{abstract}
The paper reviews the available data on the electrical and mechanical properties of zirconiagraphene composites. The effects of the graphene additive type, synthesis approach, and graphene additive contents are analyzed in terms of these composites application in solid oxide fuel cells.
\end{abstract}

\section{INTRODUCTION}

Due to their unique mechanical, thermal and electrical properties, materials based on zirconia and its solid solutions are widely used in modern technology as construction ceramics, refractory materials, and solid electrolytes. Fluorite-like cubic solid solutions stabilized by yttrium oxide $\mathrm{Y}_{2} \mathrm{O}_{3}$ (YSZ) are considered as very perspective materials due to following attractive properties: electrical conductivity of $0.1 \mathrm{~S} / \mathrm{cm}$ and oxygen transfer number $\sim 1$ at $1000{ }^{\circ} \mathrm{C}$; these electrical properties are coupled with chemical and thermal stability of the material at such a high temperature giving the opportunity to use the material as a solid electrolyte in Solid Oxide Fuel Cells (SOFC), in-situ sensors for monitoring the completeness of the oxygen burning (Lambda probes), insitu high temperature sensors for the oxygen partial pressure control in metallurgy and glass industry, etc.

However, the above advantages of YSZ are coupled with a number of drawbacks: insufficient conductivity at low temperatures, material degradation at high temperatures due to continuing grain growth, recrystallization, and interaction with cathode and an- ode materials. These drawbacks are the basic factors limiting the development of a new generation of electrochemical devices with increased efficiency. Thus, the problem of YSZ modification is quite actual.

The possible pathway of such modification can be the development of YSZ-based composites with graphene - the material that is characterized by wellknown unique mechanical and electrical characteristics: Young modulus of $~ 1000 \mathrm{GPa}$ [1], charge carriers mobility of $\sim 15000 \mathrm{~cm}^{2} / \mathrm{V}$ [2], and a zero bandgap [3].

At the moment, studies on graphene introduction in the zirconia-based systems are incomplete and the reported results are contradictory. The task of the work was to analyze the available data on zircona-graphene composites focusing on the following points: interpretation of the joint mechanisms the composites conductivity, the perspective application of such materials as oxygen pumps and galvanic elements resulting from the oxygen ions transition through the ceramic membrane providing the required oxygen partial pressure [4], and the effect of 2D material graphene on the mechanical properties of the materials.

Corresponding author: A.G. Glukharev, e-mail: gluharev1@gmail.com

(C) ITMO University, 2020 


\subsection{Abbreviations used}

YSZ - yttria stabilized zirconia, cubic $\mathrm{ZrO}_{2}$-based solid solution stabilized by 8-9 mol.\% $\mathrm{Y}_{2} \mathrm{O}_{3}$; SOFC - Solid Oxide Fuel Cell; EMF - ElectroMotive Force; $\mathbf{t}-\mathbf{Z r O}_{2}-$ tetragonal $\mathrm{ZrO}_{2}$ modification; $\mathbf{c}-\mathbf{Z r O}_{2}-$ cubic $\mathrm{ZrO}_{2}$ modification; 3YTZP - 3 mol. \% yttria tetragonal zirconia polycrystal, tetragonal $\mathrm{ZrO}_{2}$-based solid solution stabilized by 3 mol.\% $\mathrm{Y}_{2} \mathrm{O}_{3}$; SPS - Spark Plasma Sintering; FLG - few layer graphene, graphene with the number of layers of 3-10; GNP - Graphene Nanoplatelets, another abbreviation for FLG; GNR - Graphene Nanoribbons, graphene sheets with a typical width of $\sim 50 \mathrm{~nm}$ and length of $\sim$ micrometers; CNF - carbon nanofibers; GO - graphene oxide; rGO - reduced graphene oxide; ANFC - graphene coated alumina nanofibers.

\section{ZIRCONIA-BASED SOLID SOLUTIONS}

Zirconia-based solid solutions with $\mathrm{Y}_{2} \mathrm{O}_{3}$ are characterized by a complex formation mechanism. Following the well-known phase-diagram (see, e.g. [5]) and the analyses reported in [6], zirconium ion dimension (ionic radius of $0.83 \AA$ ) is not sufficient for cubic cell formation; however, the addition of relatively large yttrium ion (ionic radius of $0.96 \AA$ ) makes it possible; as a result, cubic cell is stabilized. The maximal region of fluorite-like cubic solid solution existence is available at 8-9 $\mathrm{Y}_{2} \mathrm{O}_{3}$ mol.\% addition. Such a replacement of $\mathrm{Zr}^{4+}$ by $\mathrm{Y}^{3+}$ is characterized by the formation of oxygen vacancy in the nodes of the crystal lattice following Reaction (1); as seen from the reaction, two replacing yttrium ions form one oxygen vacancy.

$$
Y_{2} \mathrm{O}_{3} \stackrel{\mathrm{ZrO}_{2}}{\longrightarrow} 2 Y_{\mathrm{Zr}}^{\prime}+3 \mathrm{O}_{o}^{x}+\mathrm{V}_{o}^{*}
$$

The addition of 3-4 mol.\% of $\mathrm{Y}_{2} \mathrm{O}_{3}$ results in the tetragonal zirconia polycrystal formation; in contrast to YSZ it is usually called 3 mol.\% tetragonal zirconia polycrystall (3YTZP). This form is less stable than YSZ due to narrow concentration region of the tetragonal solid solution existence and due to possible phase transition into the monoclinic form $\left(\mathrm{t}-\mathrm{ZrO}_{2} \rightarrow \mathrm{m}-\mathrm{ZrO}_{2}\right)$ even at low heating or mechanical impact. The comparison of the mechanical properties of YSZ and 3YTZP is given in Table 1 .

Table 1. The comparison of the mechanical properties of YSZ and PSZ.
As seen from the Table, the PSZ fracture toughness is fairly high. However, the above-mentioned transition into the monoclinic phase does not allow the full use of this property. To prove this fact, we can mention paper [10] reporting the possibility of spontaneous transition at low temperature $<120^{\circ} \mathrm{C}$ without any external impacts, under the water vapor ambience only.

Let us briefly discuss the mechanisms of the YSZ conductivity. The electronic conductivity in the fluoritelike cubic solid solutions is realized via the so called "hopping mechanism" of the oxygen vacancies which is a thermoactivated process. To realize such a mechanism, electrolyte should possess a relatively high free internal cell space along with a low defect migration enthalpy $<1 \mathrm{eV}$ [11].

In turn, the ionic conductivity in YSZ depends on many factors: temperature, defects dissociation, oxygen partial pressure, Yttria contents, and even on the synthesis approach. The temperature dependence of the ionic conductivity s can be described by Arrhenius equation:

$\sigma T=A \exp \left(-\frac{E_{a}}{k T}\right)$,

where $A$ is a pre-exponential factor and $E_{a}$ is the activation energy of the ionic conductivity. In turn, the ionic conductivity can be described in terms of charge carriers concentration $C_{i}$, their mobility $\mu_{i}$, and charge $q$. For the pure oxygen conductors $C_{i}$ is a function of the $\mathrm{O}^{2-}$ ions concentration and can be written as:

$\sigma_{i}=C_{i} \mu_{i} q_{i}$

For the pure ionic conductors $C_{i}$ is characterized by a number of oxygen ions in the unit of a crystal volume $N_{0}$ and a part of oxygen vacancies in the lattice $\left[V_{o}^{*}\right]$ :

$C_{i}=\left(1-\left[V_{o}^{*}\right]\right) N_{o}$.

The mobility of the charge carriers depends on the diffusion rate $D_{i}$ :

$\mu_{i}=\frac{q_{i} D_{i}}{k T}$.

In turn, the diffusion rate can be written as a function of migration enthalpy $\left(\Delta H_{m}\right)$ and entropy $\left(\Delta S_{m}\right)$, ion hop distance $(a)$, respective lattice vibration frequency $\left(v_{0}\right)$,

\begin{tabular}{lll}
\hline & YSZ & 3YTZP \\
\hline Vickers hardness $(\mathrm{HV})$ & $14.3-15.4[7]$ & $13.02 \pm 1.05[8]$ \\
Fracture toughness $\left(\mathrm{MPa} \cdot \mathrm{m}^{1 / 2}\right)$ & $3.61[7]$ & up to $15[9]$ \\
\hline
\end{tabular}




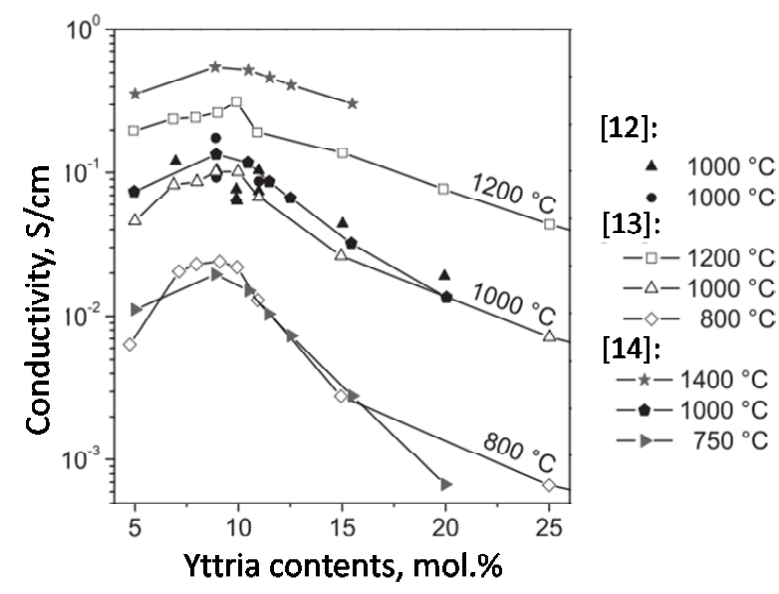

Fig. 1. YSZ conductivity at high temperatures - comparison of the data reported in [12-14].

and vacation concentration in the cell unit volume $\left(\left[V_{o}^{\prime}\right] N_{o}\right)$ :

$D_{i}=a^{2} v_{0}\left[V_{o}^{\prime}\right] N_{o} \exp \left(\frac{\Delta S_{m}}{k}\right) \exp \left(-\frac{\Delta H_{m}}{k T}\right)$.

Substituting (3)-(6) into (2), one can obtain the complete expression for the Arrhenius equation of the ionic conductivity:

$\sigma_{i} T=A\left[V_{o}^{*}\right]\left(1-\left[V_{o}^{*}\right]\right) \exp \left(-\frac{\Delta H_{m}}{k T}\right)$,

where the pre-exponential factor $A$ can be written as:

$A=\left(\frac{4 e^{2}}{k}\right) a^{2} v_{0} N_{o} \exp \left(\frac{\Delta S_{m}}{k}\right)$.

For a relatively low defect concentrations $\left[V_{o}^{\prime \prime}\right]$, the latter equation takes a form of:

$\sigma_{i} T=A\left[V_{o}^{*}\right] \exp \left(-\frac{\Delta H_{m}}{k T}\right)$.

Thus, the ionic conductivity linearly depends on the oxygen vacancies concentration and exponentially depends on the migration enthalpy. As it was mentioned above, two $\mathrm{Y}$ atoms incorporated into zircona produce one vacancy, so, the conductivity should be a linear function of $\mathrm{Y}_{2} \mathrm{O}_{3}$ contents with a tilt angle $\sim 1 / 2$. Fig. 1 demonstrates the comparison of the experimental data on YSZ conductivity according the data reported in $[12,13,14]$.

As can be seen from the figure, the high temperature YSZ conductivity is linearly increasing with the increase in $\mathrm{Y}_{2} \mathrm{O}_{3}$ contents up to 8-10 mol.\%; the decrease in the conductivity values is observed at higher yttria contents. The presented data agree with above statement on the maximal conductivity of the fluorite-like cubic solid solution (completely stabilized zirconia). The $\mathrm{Y}^{3+}$ ions concentration increases at higher $\mathrm{Y}_{2} \mathrm{O}_{3}$ contents (over $8-10 \mathrm{~mol} \%$ ), as a result, their migration becomes difficult. In turn, the total conductivity decreases $[15,16]$.

On the other hand, conductivity is not determined by $\mathrm{Y}_{2} \mathrm{O}_{3}$ contents only. As it was mentioned above, it is also affected by the oxygen partial pressure, synthesis approach (in fact, thermal and mechanical history), and material microstructure. Let us briefly consider these factors.

Generally, the oxygen ions diffusion is directly connected with the oxygen partial pressure $\left(p_{\mathrm{O} 2}\right)$, in the case of SOFC, the $p_{\mathrm{O} 2}$ difference between anode and cathode is a driving force of SOFC work. On the other hand, the oxygen ions of the $\mathrm{ZrO}_{2}$ crystal lattice could leave it at low oxygen partial pressures (see Reaction (10) below) providing the formation of two free electrons which are localized near the cations. These electrons can move forming the electron conductivity.

$\mathrm{O}_{\mathrm{o}}^{\mathrm{x}} \leftrightarrow \mathrm{V}_{\mathrm{o}}^{\prime \prime}+\frac{1}{2} \mathrm{O}_{2}+2 e^{\prime}$

The effect of microstructure and grain boundaries size follows from the fact that the complete ionic conductivity is a sum of two inputs: the grain's conductivity (the conductivity of the grain bulk) and the grain boundary one; usually, the grain boundary conductivity is two orders of magnitude lower than the grain's conductivity. The estimates of the above inputs can be carried out by the electrochemical impedance spectroscopy method based on the study of the complete electrical resistance of the material as a function of the applied AC frequency.

The conductivity activation energies for the grain and grain boundary conductivities also differ. According to $[17,18], E_{a}$ calculated for grain and grain boundary conductivity are $0.81-0.84$ and 1.0-1.04 eV, respectively (data calculated for zirconia with 1.7-2.9 mol.\% $\mathrm{Y}_{2} \mathrm{O}_{3}$ ). As for grain boundary oxygen conductivity, it depends on the dopant contents, lattice mismatch, surface charge, presence of microcracks, etc. [19].

A lot of works are reporting the material synthesis modification aiming the increase in the complete YSZ conductivity. Authors of [20,21] reported the improvement of the baking regimes; the decrease in the complete conductive activation energy from 0.83 to $0.69 \mathrm{eV}$ at high temperatures and from 1.03 to $0.8 \mathrm{eV}$ at low temperatures was stated. The conclusion on the effect of the grain growth is done in these works: submicron grains were obtained at the decrease of the baking temperature down to $1200{ }^{\circ} \mathrm{C}$. As a result, the total grain surface was significantly increased. Another approach 
Table 2. Comparison of the results obtained for different GO (RGO) reduction approaches.

\begin{tabular}{|c|c|c|c|}
\hline Reduction approach & $\mathrm{C} / \mathrm{O}$ ratio & Conductivity, S/cm & Reference \\
\hline \multicolumn{4}{|l|}{ Chemical reduction by } \\
\hline Hydrazine hydrate & 10.3 & 2 & [29] \\
\hline Hydrazine vapor & 8.8 & - & [30] \\
\hline Vitamin C & 12.5 & 77 & [31] \\
\hline 150 mmole $\mathrm{NaBH}_{4}$ solution for 2 hours & 8.6 & 0.05 & [32] \\
\hline $\mathrm{Zn}, 4 \mathrm{M} \mathrm{H}_{2} \mathrm{SO}_{4}$ for 2 hours & 21.2 & 34.16 & [33] \\
\hline \multicolumn{4}{|l|}{ Multistep: } \\
\hline (1) $\mathrm{NaBH}_{4}$ solution & 4.8 & 0.82 & [34] \\
\hline (2) Concentrated $\mathrm{H}_{2} \mathrm{SO}_{4}, 120^{\circ} \mathrm{C}, 12$ hours & 8.6 & 16.6 & \\
\hline (3) Annealing in $\mathrm{Ar} / \mathrm{H}_{2}$ at $1100{ }^{\circ} \mathrm{C}$ & $>246$ & 202 & \\
\hline \multicolumn{4}{|l|}{ Hydrothermal methods } \\
\hline Hydrothermal reduction at $160^{\circ} \mathrm{C}$ for 4 hours & - & $8.3 \cdot 10^{-4}$ & {$[35]$} \\
\hline \multicolumn{4}{|l|}{ Thermal approaches } \\
\hline Annealing at $900^{\circ} \mathrm{C}$ in vacuum & - & 14.1 & {$[30]$} \\
\hline Annealing at $1100^{\circ} \mathrm{C}$ in vacuum & - & $10^{3}$ & [36] \\
\hline Annealing at $1100^{\circ} \mathrm{C}$ in $\mathrm{Ar} / \mathrm{H}_{2}$ & - & 727 & [37] \\
\hline Microwave reduction & $<11.4$ & $<1.2 \cdot 10^{4}$ & {$[38]$} \\
\hline
\end{tabular}

reported in [22-24] is the addition of some special agents that can be concentrated on the grain boundaries giving rise to their modification. Authors of [25] demonstrated the effects of multi-step baking that included the step of intermediate annealing at $1200{ }^{\circ} \mathrm{C}$ for $10-40$ hours; however, further increase in the annealing temperature as well as the increase in the annealing duration did not show additional effect.

\section{PECULIARITIES OF THE GRAPHENE INTRODUCTION INTO THE COMPOSITES}

The unique properties of graphene mentioned in the Introduction section are well-known due to numerous studies, so, their discussion here looks redundant. In this Section, we would like to focus on the peculiarities of the graphene introduction into the composites considered as industrial materials.

First, it should be mentioned that the practical use of monolayered graphene is usually quite difficult or impractical due to a number of reasons. At first, the production of pure defect-free monolayered graphene is expensive and labor intensive. Second, the excess surface energy of the pure graphene separated from the wafer makes it unstable to torsion. So, it is reasonable to use some graphene derivatives or graphene-containing materials for industrial applications. Surely, the use of such substituting materials is reasonable when their production cost is much lower than that of pure monolayered graphene and the difference between their properties and graphene properties is minimal. The following materials that meet these criteria should be mentioned: few layer graphene (FLG) - graphene fragments with the number of layers of 3-10, also known as graphene nanoplatelets (GNP), graphene nanoribbons (GNR) narrow graphene ribbons with the width lower than 50 $\mathrm{nm}$ at the length of micrometers, they can be produced from carbon nanotubes. A group of materials characterized by relatively simple synthesis approach should be mentioned - single layer graphene sheets with some defects: functional groups, dot defects, structure distortions, etc. Among these materials, the graphene oxide $(\mathrm{GO})$ and the reduced graphene oxide (rGO) should be mentioned due to their production simplicity. In addition, GO and RGO are hydrophilic and form suspensions in water, this makes their use in the composites production technology rather easy. On the other hand, graphene oxidation results in the increase in the interlayer distance from $3.35 \AA$ to $\sim 7 \AA$ [26]. At present, more than five models of GO (RGO) structures are suggested, none of them became generally accepted. The carbon-to-oxygen $(\mathrm{C} / \mathrm{O})$ ratio is usually used to characterize the oxidation completeness, it varies from 10 or even more for low oxidized materials to 2.1 for the case of maximal oxidation [27]. Modified Hummers method is usually applied to oxidize graphite, see. e.g. [28]; it can 
be simply exfoliated to graphene oxide by heating or mechanical impact.

A number of approaches were suggested for further GO (RGO) reduction; it should be noted that none of them provides the complete reduction: usually, some residual carboxyl groups as well as defects resulting from their reduction are present in the final product. The best results obtained are $\mathrm{C} / \mathrm{O}$ ratio of $12-14$ and relative conductivity up to $10^{4} \mathrm{~S} / \mathrm{cm}$, see Table 2 .

As seen from the table, the obtained results are contradictory. However, we can conclude that most of the approaches applied provide $\mathrm{C} / \mathrm{O}$ ratio higher than 8 ; high temperature annealing in the reduction atmosphere (argon-hydrogen) seems to be the most effective here. In contract, the spread of the conductivity values is quite impressive; its analysis should be a point of a separate review.

It should be noted that practical implementation of the different reduction approaches faces individual advantages and drawbacks typical for each method. Chemical reductions are simple in realization, in addition, there is no necessity in high temperatures. However, some of these methods are toxic and explosive, in addition, high rGO coagulation is typical here. Hydrothermal and thermal methods give the opportunity to obtain better $\mathrm{C} / \mathrm{O}$ ratio (up to 15-18), but the production of graphene sheets with a large surface is quite difficult here, in addition, the reduction of thin films is practically impossible. Generally, the higher is the reduction temperature, the higher is the obtained conductivity, see Fig. 2. Obviously, the type of the atmosphere is important here, since reduction process releases oxygen, vacuum or reduction atmosphere should be used.

Summarizing the above consideration, one can conclude that the type of the graphene derivative and the approach used for its production will significantly affect the graphene-containing composites properties. The balance between the process simplicity and low cost and the final composite properties should be chosen for industry applications.

\section{ZIRCONIA-GRAPHENE COMPOSITES}

The addition of the graphene to oxide and non-oxide ceramics could significantly improve the material properties $[39,40]$, hence, the development of "ceramicsgraphene" composites is the important task of modern science.

\subsection{Synthesis}

The first step of the "zirconia-graphene" synthesis is the initial powder mixing. It could be realized in a number of modifications.

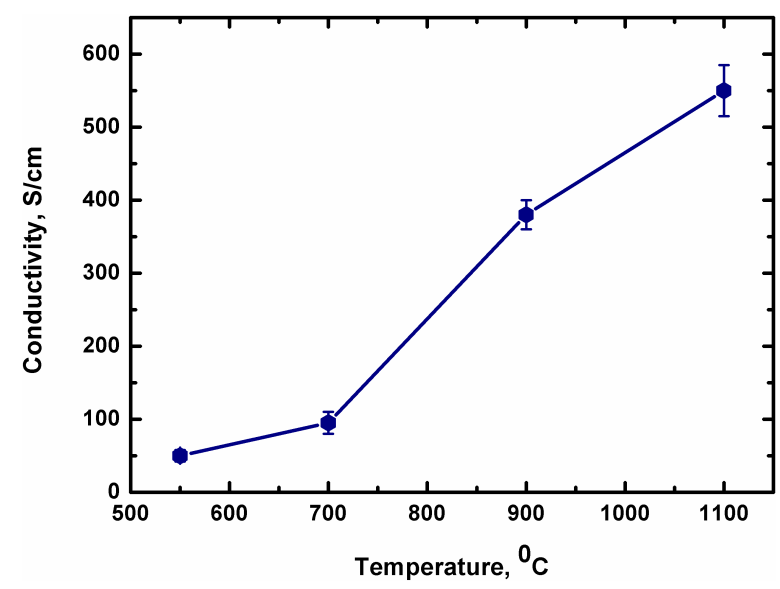

Fig. 2. rGO conductivity vs reduction temperature, recalculated data from [37].

(1) Dry milling. Dry milling is carried out in planetary ball mills, this approach in case of $\mathrm{ZrO}_{2}$ is limited by the fact that zirconia possesses high hardness; so, the conventional steel vessels with steel balls can not be used here. In additions, dry milling is usually accompanied by the significant temperature increase leading to partial GO reduction; to prevent it, neutral gas atmosphere is recommended.

(2) Liquid mixing. This approach in conventionally realized in a following way. Ceramic precursor powder and graphene derivative are dispersed separately in the same solvent. Mixing conditions here are selected accounting for particle size distribution, solvent type, surfactants presence, etc.; mixing is carried out by mechanical or magnetic stirrers, or by ultrasound mixing $[41,42,44]$. In some cases, the ceramic-containing solvent is added to the graphene derivative suspension $[44,45]$. Sometimes, wet precursor and graphene derivative powders are mixed via ball milling in the planetary mills $[46,47]$. Water can be used as a solvent in case of GO usage, the use of organic solvents is rarely mentioned, see, e.g. [48]. On the contrary, the use of graphene, GNP, and GNR requires organic solvents application, the use of water with surfactants is also possible, but not optimal [49]. The important step of this method is drying: spray drying, freeze-drying, and rotary evaporation are used to decrease agglomeration and separation of the powder mixture. It should be noted that the use of liquid mixing is rather limited in case of $\mathrm{ZrO}_{2}$ based composites due to specific problems with suspension formation.

(3) Sol-gel methods. Generally, sol-gel approach could result in the excellent components mixing up to molecular level, water GO suspensions could be used as carbon-containing additives here. The idea of such method is the formation of hydroxides in the carbon-containing suspension which are acting as the crystallization centers [50]. Another possibility is the addition of GO to freshly 


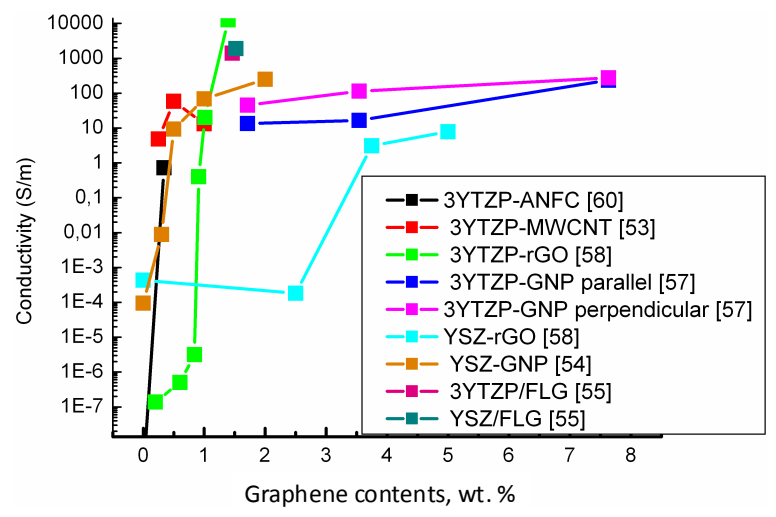

Fig. 3. Ceramics conductivity vs graphene contents at room temperature, where: $3 \mathrm{YTZP}-3 \mathrm{~mol} . \% \mathrm{Y}_{2} \mathrm{O}_{3}$ tetragonal $\mathrm{ZrO}_{2}$; $\mathrm{YSZ}-8$ mol. $\% \mathrm{Y}_{2} \mathrm{O}_{3}$ cubic $\mathrm{ZrO}_{2}$; $\mathrm{ANFC}$ - $\mathrm{Al}_{2} \mathrm{O}_{3}$ nanofibers covered by graphene, data from [53$55,57,58,60,67]$.

precipitated hydroxide sol [51]. It should be mentioned that in spite of the fact that the described method is quite promising, the number of investigations in this field is limited.

The prepared powder mixture is then baked; the most effective approach here is Spark Plasma Sintering (SPS) since the limited process duration prevents the reactions between zirconia and carbon-containing phase, carbon burning, and thermal degradation of the material. In addition, SPS of zirconia-GO powders results in GO reduction to $\mathrm{rGO}$ giving the opportunity to omit the reduction step in the production process [52]. Hot pressure / hot isostatic pressure are used less often, while the conventional baking without pressing is quite a rare approach.

\subsection{Electrical characteristics of $\mathrm{ZrO}_{2}$-graphene composites}

Graphene, possessing the extra-high values of the charge carriers mobility $\left(15000 \mathrm{~cm}^{2} / \mathrm{V}\right.$ [2-6]), is an excellent electronic conductor. It is evident that the graphene addition to a ceramic matrix should decrease its electrical resistance. However, this effect is not significant till the graphene contents in the material is reaching some specific value, see Fig. 3. This value - percolation threshold - is the minimal contents that is necessary for the formation of the connected and extended 3D net of the graphene subphase; this subphase provides the material conductivity. For the zirconia-based systems such an increase in the material conductivity is 4-8 orders of magnitude.

The further graphene contents increase over the percolation threshold value does not produce any significant increase in the material conductivity and its value reaches a plateau. We should note that such a tendency is observed for all ceramic materials; the conductivity of pure dielectrics $\left(\mathrm{Si}_{3} \mathrm{~N}_{4}, \mathrm{Al}_{2} \mathrm{O}_{3}, \mathrm{AlN}\right)$ at that increases up to 8 orders of magnitude, while for the ceramics possessing their own conductivity such an increase is shown to be 3-4 orders of magnitude [39].

The experimental dependencies could be approximated by a simple percolation model as:

$$
\sigma_{e}=\sigma_{e(\text { graphene) }}\left(V_{h}-V_{h, c}\right)^{t} \text {, }
$$

where $\sigma_{e}$ and $\sigma_{e(\text { graphene })}$ are the conductivities of the composite and the conducting phase (graphene), respectively, $V_{h}$ is a volume fraction of the conductive additive, $V_{h, c}$ is the critical volume (the volume necessary for percolation onset), and $t$ - the empirical parameter describing the connectedness of the conductive phase. It should be noted that the application of the above model is limited - is can be used only for the systems with $V_{h}>V_{h, c}$ and near the $V_{h, c}$ point. Another approximation models can be developed basing on the effective mediums [43] or simple mixing rule [56].

Another typical feature of the zirconia-graphene composites is the anisotropy of the conductivity resulting from the preferable orientation of the graphene sheets in the composite. This feature is quite evident in case of SPS use since the method is directed and it has a compression axis. The parallel $\sigma_{\|}$and $\sigma_{\perp}$ perpendicular inputs into the conductivity are usually considered, their directions are treated relatively to the direction of the compression axis. The ratio of these conductivities is usually characterized by so-called anisotropy factor $\sigma_{\|} / \sigma_{\perp}$, for zirconia-graphene systems it can vary in a wide range, see Table 3.

The difference in the percolation threshold value could be due to the different characteristics of the precursor powders used for composites synthesis; but the form of the graphene sheet used seems to be the dominant factor here. As follows from the data reported in [59], the optimal percolation threshold value of 0.34 vol.\% GO and the conductivity of $10^{3} \mathrm{~S} / \mathrm{m}$ at $2.35 \mathrm{vol} . \%$ $\mathrm{GO}$ contents could be obtained for $\mathrm{Al}_{2} \mathrm{O}_{3}-\mathrm{GO}$ system due to the use of the colloidal synthesis providing the high uniformity of GO distribution at the grain boundaries. The authors of the paper stated that the optimal GO sheet shape that could result in the minimal percolation threshold value of 0.13 vol.\% GO is a fiber with the length-to-width ratio of $\sim 1000$. Such an additive in a form of $\mathrm{Al}_{2} \mathrm{O}_{3} / \mathrm{GO}$ nanofibers (ANFC) was used for the $3 Y$ YZP ceramics modification in [60]. As a result, conductivity of $0.72 \mathrm{~S} / \mathrm{m}$ at such a low graphene additive contents as 5 vol.\% ANFC (0.34 wt.\% GO). The percolation threshold here was also significantly lower than the values reported in the most of works on zirconiagraphene systems. Graphene nanoribbons obtained as 
Table 3. Conductivities and anisotropy factor in the zirconia-graphene systems.

\begin{tabular}{llllll}
\hline $\begin{array}{l}\text { Ceramic } \\
\text { matrix }\end{array}$ & $\begin{array}{l}\text { Graphene-containing } \\
\text { additive / Temperature }\end{array}$ & $\sigma_{\|}\left(\mathrm{S} \mathrm{m}^{-1}\right)$ & $\sigma_{\perp}\left(\mathrm{S} \mathrm{m}^{-1}\right)$ & $\sigma_{\|} / \sigma_{\perp}$ & Reference \\
\hline 3 YTZP & 5 vol.\% GNP/298 K & $13.49 \pm 0.09$ & $45.3 \pm 0.3$ & $3.36 \pm 0.05$ & {$[57]$} \\
& 5 vol.\% GNP/750 K & 18.2 & 55.5 & 3.04 & $6.84 \pm 0.11$ \\
& 10 vol.\% GNP/298 K & $16.57 \pm 0.11$ & $113.3 \pm 1.1$ & 4.22 & $1.18 \pm 0.05$ \\
& 10 vol.\% GNP/750 K & 24.6 & 104 & 1.32 & 11.13 \\
& 20 vol.\% GNP/298 K & $234 \pm 7$ & $275.9 \pm 1.9$ & {$[58]$} \\
YSZ & 20 vol.\% GNP/750 K & 211 & 279 & 10.87 \\
\hline
\end{tabular}

a result of carbon nanotubes breaking can be also used here since the geometry of the obtained GO ribbons is similar to that in the case of ANF [61].

Note that the above considerations deals with the electrical characteristics of zirconia-graphene composites at room temperature where the ionic conductivity of stabilized zirconia is negligible and it can be treated as a dielectric. However, this ionic conductivity at high temperatures increases: it can reach $0.1 \mathrm{~S} / \mathrm{cm}$ for cubic YSZ and this value is quite comparable with the electronic conductivity that appears in the ceramic composites due to the graphene additives. So, zirconia-graphene composites at high temperatures should possess the Mixed Electronic-Ionic Conductivity (MIEC). Such a mixed conductivity is well known for $\mathrm{ABO}_{3}$ perovskites where $\mathrm{B}$ is a transition metal. Such materials are used in SOFCs [62], oxygen transport membranes [63], additional catalyst layers [64] and some other applications. Since the exploitation conditions here are $600-900{ }^{\circ} \mathrm{C}$ and oxygen atmosphere, the lifetime of the devices using perovcskite materials is rather low due to their relatively low chemical resistance.

YSZ-graphene composites possessing high chemical and phase stability in the above temperature range in the reactive atmosphere are considered as the excellent MIEC materials with the potential to substitute perovskite materials in most of the applications discussed.

Let us briefly consider the minimal requirements for the SOFC cathode material. They are: (i) the presence of the electronic conductivity; (ii) ionic conductivity is desirable; (iii) chemical and phase stability at high temperatures in the oxygen ambience; (iv) thermal expansion coefficient close to that of solid electrolyte (YSZ); (v) the absence of chemical interaction between the cathode material and the electrolyte. With respect to the above requirements, YSZ-graphene composites seem to be ideal candidates here. Thus, the study of YSZgraphene composites synthesis, their electrical proper- ties, conductivity mechanisms at high temperatures, phase and chemical stability in inert, oxidation, and reduction atmospheres are the point of essential interest. However, the number of the works in this field is fairly limited till now $[57,58,65]$; summary of the available results on the conductivity of the zirconia-graphene systems is shown in Fig. 4. As seen from the figure, the composites conductivity at temperature increase can both be increased or decreased; however, this effect is low (less than 5\%). Such a change is due to the processes taking place in the graphene-containing phase. Similarly to graphite [66], graphene can demonstrate metallic or semiconductor properties depending on the number of the structure defects. The temperature increase in the case of the high structure defects number will favor the increase in the probability of the electron overcoming a potential barrier of the movement through the defect. The graphene behavior here is well described by the Motts conductivity model in the variable range hopping (VRH) regime [57].

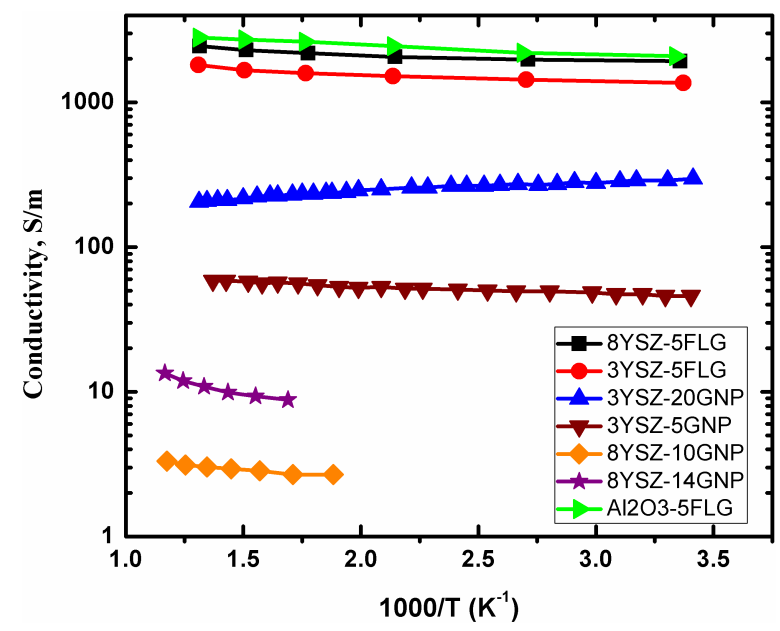

Fig. 4. Temperature dependence of zirconia-graphene composites conductivity in comparison with the $\mathrm{Al}_{2} \mathrm{O}_{3}$ GNP composite, summary of [57,58,65]. 
The conductivity values here are dependent not on the ceramic matrix type and its own conductivity, but, similarly to the case of conductivity at room temperature, they depend on the type and shape of the graphene additive. However, authors of [65] have demonstrated that the ceramic matrix can affect the composite conductivity via the interaction of the matrix oxygen vacancies (even in the case these vacancies are not mobile) with charge carries of the graphene - electrons. The vacancy can accept the electron from graphene, as a result, two initial states for electron and vacancy are replaced by a single state of the hole conductivity with the Fermi level lower that conductivity zone; in turn, the total composite conductivity is decreased.

To prove the above suggestions, the authors of [65] investigated the temperature dependencies and thermal Electro-Motive Force (EMF) for a number of ceramic matrix components with 5 vol.\% of FLG, see Fig. 5. The initial particle sizes in the precursor powders as well as the final grain sizes in the composites were equal, hence, the structure effect was excluded. The amount of the oxygen vacations was as follows: $\mathrm{Al}_{2} \mathrm{O}_{3}<3$ YTZP $<8$ YSZ. As seen from Fig. 5a, $\mathrm{Al}_{2} \mathrm{O}_{3}-5 \mathrm{FLG}$ possesses the highest conductivity in spite of a rather high ionic conductivity of 8 YSZ-5FLG composite. The values obtained for thermoEMF (the Seebeck effect) were of different signs for pure $\mathrm{GO}$ baked by SPS and $\mathrm{Al}_{2} \mathrm{O}_{3}-5 \mathrm{FLG}$ composite (negative) and for zirconia-graphene components (positive), see Fig. 5b; the authors consider this fact as being due to the difference in the conductivity types. The higher 8YSZ-5FLG values of conductivity and thermal EMF than those registered for 3YTZP-5FLG were not discussed; we assume them as a result of the YSZ ionic conductivity. It should be noted that the conductivity anisotropy maintained in all the temperature range, see the results reported in [57] for 3YTZP matrix composites with 5, 10, and $20 \mathrm{vol} \%$ GNP; the anisotropy factor remains constant for all composites at 298-750 K.

\subsection{Mechanical properties of zirconia- graphene composites}

Generally, the factors limiting the ceramic composites application as a construction material are their fracture toughness characterized by $K_{1 \mathrm{C}}$ parameter and hardness; the addition of graphene is assumed as a promising pathway to improve these characteristics. However, the experimental data reported in, e.g. [67,68], see Fig. 6 and Table 4 are contradictory.

These discrepancies could be due to the following reasons. First, the conventional approach to determine the Vickers hardness is the indentation by the diamond prism with $136^{\circ}$ angle and further measurements of radial cracks. Zirconia-graphene composites are aniso-
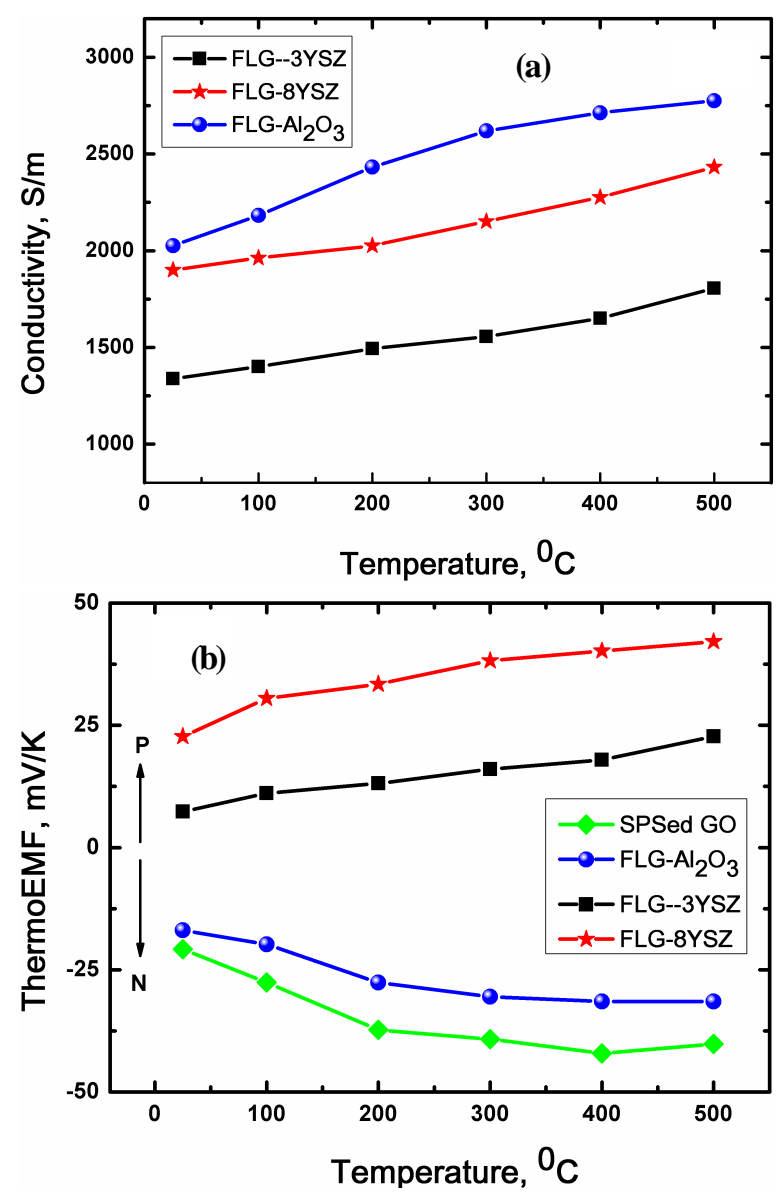

Fig. 5. Temperature dependencies of (a) conductivity and (b) thermal EMF for $\mathrm{Al}_{2} \mathrm{O}_{3}-5 \mathrm{FLG}, 8$ YSZ-5FLG, and 3YTZP-5FLG composites, according to data reported in [65].

tropic materials where the radial cracks could be rather small or, sometimes, absent, see, e.g. [69]. The nature of the graphene additive (rGO, CNP, FLG, etc.) could also affect the mechanical characteristics. The grain size distribution, composite microstructure, and the uniformity of the graphene additive distribution in the zirconiagraphene composites (these characteristics depend on the synthesis approach and, mainly, on the thermal history of the material) also affect the hardness and fracture toughness of the materials.

Authors of $[67,68,70]$ reported the improvement of the fracture toughness even at low amounts of the graphene-containing additives. SPS sintered 3\% YTZPrGO composites were studied in [67]. As seen from Fig. 6 , the fracture toughness in these composites increases with the RGO contents increase, while the Vickers hardness shows some decrease. Conventionally, the decrease changes are explained in terms of the grain size changes: the less is the average grain size, the higher is the material hardness. However, the average grain size of the composite matrix in [67] was decreasing with the RGO 

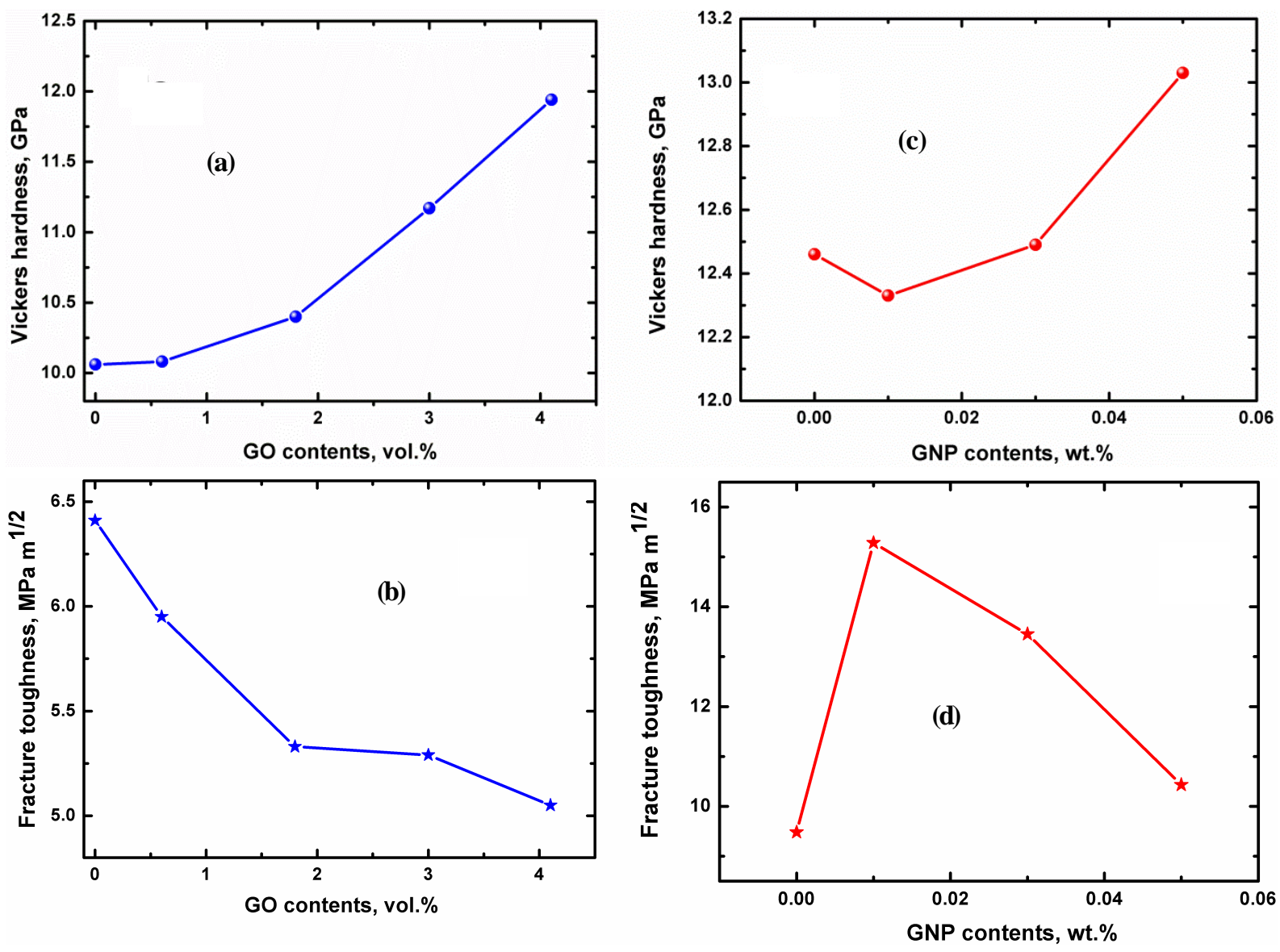

Fig. 6. The comparison of the data on Vickers hardness (a) - replotted from [67] and (c) replotted from [68] and fracture toughness (b) replotted from [67] and (d) replotted from [68] for zirconia graphene composites.

contents increase. The authors of the paper considers the hardness decrease here as being due to the density decrease coupled with the residual porosity increase. However, this statement contradicts the reported density measurements: for all composites studied it was estimated as $98 \%$ of the theoretical one. The fracture toughness parameter reported for pure YSZ in [67] was 4.4 $\mathrm{MPa} \mathrm{m}^{1 / 2} .4 .1 \% \mathrm{rGO}$ addition increases this value up to $5.9 \mathrm{MPa} \mathrm{m}^{1 / 2}$, this improvement is more than in case of zirconia - carbon nanotubes composites. The authors assumes this effect as a result of grains "wrapping" by $2 \mathrm{D}$ graphene sheets with the formation of so-called "coreshell" composites.

Similar system based on 3 YTZP with CNP additions [68] showed higher crack-resistance values: 8.9-9.5 MPa $\mathrm{m}^{1 / 2}$ for the pure zirconia ceramics and up to $15.3 \mathrm{MPa}$ $\mathrm{m}^{1 / 2}$ for the zirconia-graphene composites. The increase in the fracture toughness due to the graphene-containing additions in the ceramic matrix is $\sim 60 \%$ here. Note, that the values of fracture toughness obtained for the composites zirconia-graphene composites in [68] are much higher (2-2.5 times) than those reported for similar zirconia matrix modified by rGO in [67], see Fig. 6. This increase can be explained by the different type of graphene-containing addition as well as by the use of another synthesis approach. Indeed, the authors of [68] applied plasma assisted sintering (PAS) instead of SPS, there are some data stating that PAS favors the impurities evaporation from the composites. The hardness of the samples is slightly increased.

Summarizing the discussion of the work, we should mention that the excellent results obtained in fracture toughness increase should be treated with regard to the fact that, in contrast to other works, the values of the fracture toughness here were determined using singleedge notched beam approach (SENB); hence, the comparison of these results with another data should account this difference. The fact that GNP addition evidently affects the fracture toughness, while the composite hardness seems to remain constant within 3-5\%, also requires additional discussion.

Paper [70] reports the study of 5YSZ matrix composite with GNP addition. The increase in the graphenecontaining additive contents in the composite up to 2.88 vol.\% (0.5 wt.\%) resulted in the increase in fracture toughness, hardness, and elasticity by $\sim 36 \%, \sim 13 \%$, and $\sim 18 \%$, respectively. However, the further increase in GNP contents led to the mechanical properties de- 
Table 4. Comparison of the data on mechanical properties and relative densities obtained for zirconia-graphene composites.

\begin{tabular}{|c|c|c|c|c|c|c|}
\hline System & $\begin{array}{l}\text { Graphene additive } \\
\text { amount, vol.\% }\end{array}$ & $\begin{array}{l}\text { Temperature, } \\
{ }^{\circ} \mathrm{C}\end{array}$ & $\begin{array}{l}\text { Relative density, } \\
\% \text { of the } \\
\text { theoretical value }\end{array}$ & $\begin{array}{l}\text { Hardness, } \\
\text { GPa }\end{array}$ & $\begin{array}{l}\text { Fracture } \\
\text { toughness, } \\
\mathrm{MPa} \mathrm{m}^{1 / 2}\end{array}$ & $\begin{array}{l}\text { Refe- } \\
\text { rence }\end{array}$ \\
\hline \multirow[t]{5}{*}{ YSZ-rGO } & 0 & 1350 & $>98$ & 12.50 & 4.4 & [67] \\
\hline & 0.6 & & & 12.0 & 4.5 & \\
\hline & 1.8 & & & 11.19 & 4.7 & \\
\hline & 3 & & & 11.19 & 5.3 & \\
\hline & 4.1 & & & 10.90 & 5.9 & \\
\hline \multirow[t]{8}{*}{ YSZ-GNP } & 0 & 1200 & $>98$ & 11.36 & 8.9 & [68] \\
\hline & & 1300 & & 12.46 & 9.5 & \\
\hline & & 1400 & & 10.95 & 9.0 & \\
\hline & 0.01 & 1200 & & 13.56 & 11.2 & \\
\hline & & 1300 & & 12.33 & 15.3 & \\
\hline & & 1400 & & 12.69 & 9.3 & \\
\hline & 0.03 & 1300 & & 12.58 & 13.5 & \\
\hline & 0.05 & 1300 & & 13.02 & 10.5 & \\
\hline \multirow[t]{4}{*}{ 5YSZ-GNS } & 0 & 1400 & $>96$ & $11.0 \pm 0.57$ & $4.1 \pm 0.22$ & [70] \\
\hline & 2.88 & & & $12.4 \pm 0.12$ & $5.6 \pm 0.06$ & \\
\hline & 4.31 & & & $12.1 \pm 0.34$ & $5.3 \pm 0.08$ & \\
\hline & 5.75 & & & $11.7 \pm 0.31$ & $4.7 \pm 0.05$ & \\
\hline 3YTZP & 0 & 1300 & $\sim 99$ & $15.7 \pm 0.2$ & $4.6 \pm 0.1$ & [71] \\
\hline 3YTZP-GO & 2 & & & $15.0 \pm 0.2$ & $5.0 \pm 0.3$ & \\
\hline 3YTZP-CNFs & 2 & & & $14.7 \pm 0.2$ & $5.3 \pm 0.3$ & \\
\hline
\end{tabular}
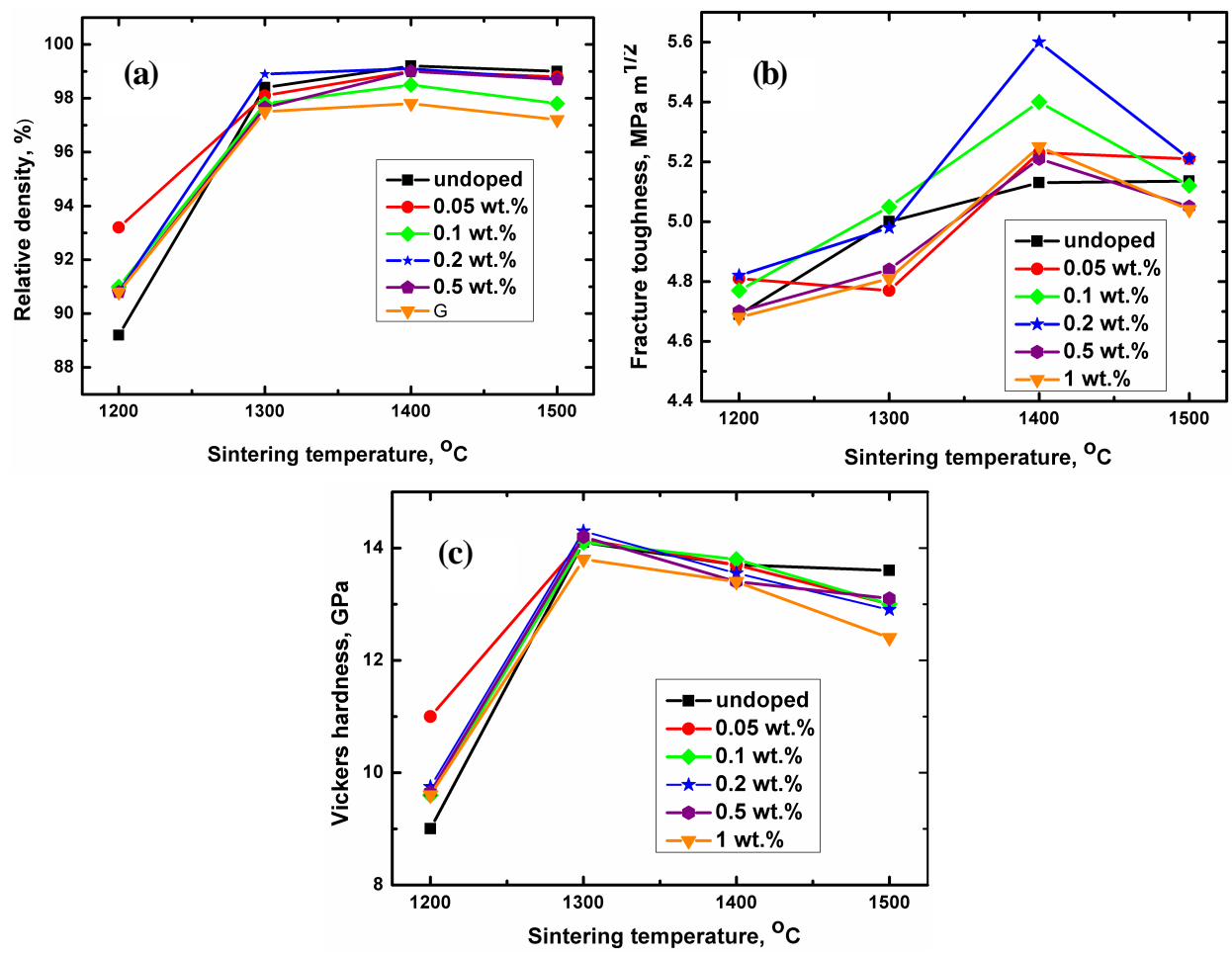

Fig. 7. Temperature dependencies of the (a) relative density, (b) fracture toughness, and (c) hardness for 3YTZP-GO composites, data replotted from [72]. 
crease, primarily, due to the decrease in the material density. The data reported in [70] agree with the results of [67].

The authors of [72] argue with the previous statements considering that the graphene-containing addition does not significantly affect the mechanical properties and crack formation mechanism, but manifests itself as a lubricant only. Zirconia-based composites here were produced by SPS synthesis, GO and GNF were used as the graphene-containing additives, the results are presented in Fig. 7.

As follows from the presented data, the crack length in case of pure 3YTZP is quite similar to that determined for the composites with up to $1 \mathrm{wt}$ \% GO addition, fracture toughness here is constant for all samples studied within the experimental error. Fig. 7 demonstrates the data on GO additions, the use of GNF gives the same effect.

Authors of [72] studied the dependencies of composite fracture toughness, hardness, and relative density on the synthesis temperature and the relative density of the final composites; it was assumed that mechanical characteristics of the samples equally depends on the graphene-amount in the composite and on its density. It should be mentioned that the important peculiarity of the discussed work was the synthesis approach: baking was carried out in air, so, one can expect the significant carbon-phase burning during the process [73]. In spite of this fact, the high composites density ( $>98 \%$ of the theoretical one) was obtained at the synthesis temperature of $1400{ }^{\circ} \mathrm{C}$. Some slight increase in the fracture toughness was also observed, while the hardness values remained constant.

\section{CONCLUSIONS}

The presented analysis prove that zirconia-graphene composites could be considered as promising materials for modern technologies; primarily, their application in Solid Oxide Fuel Cells seems quite attractive. It should be noted that the available data did not demonstrate any significant effect of graphene-containing additives on the mechanical properties of the zirconia-based composites. In particular, this effect on the fracture toughness and hardness is comparable with the effects of the synthesis approach and final ceramics density. Graphene addition in zirconia-based composites provides the onset of electronic conductivity in them, as a result, the produced materials are characterized by Mixed Electronic-Ionic Conductivity. Coupled with high chemical and phase stability, this characteristic makes zirconiagraphene composites the unique material for SOFCs and high-temperature sensors. However, the analysis of the available literature demonstrates that the data on the most promising composite based on cubic $\mathrm{ZrO}_{2}$-based solid solution stabilized by $8-9$ mol. $\%$ of $\mathrm{Y}_{2} \mathrm{O}_{3}$ are quite poor. Thus, the further investigation in this field is necessary, the effect of the synthesis approach as well as the graphene-additive type and contents should be clarified.

\section{REFERENCES}

[1] A. K. Geim and K. S. Novoselov, The rise of graphene, Nat. Mater., 2007, vol. 6, no. 3, pp. 183-191. https://doi.org/10.1038/nmat1849

[2] H. Shioyama, Cleavage of graphite to graphene, J. Mater. Sci. Lett., 2001, vol. 20, no. 6, pp. 499-500. https://doi.org/10.1023/A:1010907928709

[3] P. Shemella and S. K. Nayak, Electronic structure and band-gap modulation of graphene via substrate surface chemistry, Appl. Phys. Lett., 2009, vol. 94, no. 3, art. 032101. https://doi.org/ 10.1063/1.3070238

[4] D. Yuan and F.A. Kroeger, Stabilized Zirconia as an Oxygen Pump, Electrochem Soc-J, 1969, vol. 116, no. 5, pp. 594-600. https://doi.org/10.1149/ 1.2411972

[5] V. S. Stubican, R. C. Hink and S. P. Ray, Phase Equilibria and Ordering in the System $\mathrm{ZrO}_{2} \mathrm{Y}_{2} \mathrm{O}_{3}$, J. Am. Ceram. Soc., 1978, vol. 61, no. 1-2, pp. 17-21. https://doi.org/10.1111/j.1151-2916.1978.tb09220.x

[6] H. Yanagida, K. Komoto and M. Miyayama, The chemistry of ceramics (Wiley, 1996).

[7] A. Ghazanfari, W. Li, M. C. Leu, J. L. Watts and G. E. Hilmas, Additive manufacturing and mechanical characterization of high density fully stabilized zirconia, Ceramics International, 2017, vol. 43, no. 8, pp. 6082-6088. https://doi.org/ 10.1016/j.ceramint.2017.01.154

[8] J. Zhang, Thermal cycling effect on mechanical properties of Yttria-stabilized tetragonal zirconia, Key Engineering Materials, 2013, vol. 538, pp. 121-124. https://doi.org/10.4028/ www.scientific.net/KEM.538.121

[9] T. Masaki, Mechanical properties of toughened $\mathrm{ZrO}_{2} \mathrm{Y}_{2} \mathrm{O}_{3}$ Ceramics, J. Am. Ceram. Soc., 1986, vol. 69, no. 8, pp. 638-640. https://doi.org/10.1111/ j.1151-2916.1986.tb04823.x

[10] T. Sato and M. Shimada, Transformation of Yttria Doped Tetragonal $\mathrm{ZrO}_{2}$ Polycrystals by Annealing in Water, J. Am. Ceram. Soc., 1985, vol. 68, no. 6, pp. 356-356. https://doi.org/10.1111/ j.1151-2916.1985.tb15239.x

[11] N. Mahato, A. Banerjee, A. Gupta, S. Omar and K. Balani, Progress in material selection for solid oxide fuel cell technology: A review, Prog. 
Mater. Sci., 2015, vol. 72, pp. 141-337. https://doi.org/10.1016/j.pmatsci.2015.01.001

[12] J. M. Dixon, L. D. LaGrange, U. Merten, C. F. Miller and J. T. Porter, Electrical Resistivity of Stabilized Zirconia at Elevated Temperatures, J. Electrochem. Soc., 1963, vol. 110, no. 4, pp. 276-279. https://doi.org/10.1149/1.2425731

[13] D. W. Strickler and W. G. Carlson, Ionic Conductivity of Cubic Solid Solutions in the System $\mathrm{CaO}-\mathrm{Y}_{2} \mathrm{O}_{3}-\mathrm{ZrO}_{2}$, J. Am. Ceram. Soc., 1964, vol. 47, no. 3, pp. 122-127. https://doi.org/ 10.1111/j.1151-2916.1964.tb14368.x

[14] R. E. W. Casselton, Low field DC conduction in yttria-stabilized zirconia, Phys. Status Solidi, 1970, vol. 2, no. 3, pp. 571-585. https://doi.org/ 10.1002/pssa.19700020319

[15] J. A. Kilner and C. D. Waters, The effects of dopant cation-oxygen vacancy complexes on the anion transport properties of non-stoichiometric fluorite oxides, Solid State Ionics, 1982, vol. 6, no. 3, pp. 253-259. https://doi.org/10.1016/01672738(82)90046-7

[16] J.A. Kilner and B.C.H. Steele, Mass Transport in Anion-Deficient Fluorite Oxides, In: Nonstoichiometric Oxides, ed. by O. Toft Sørensen (Academic Press, N.Y., 1981), pp. 233-269, https://doi.org/10.1016/B978-0-12655280-5.50010-9

[17] H. L. Tuller, Ionic conduction in nanocrystalline materials, Solid State Ionics, 2000, vol. 131, no. 1, pp. 143-157. https://doi.org/10.1016/S01672738(00)00629-9

[18] P. Mondal, A. Klein, W. Jaegermann and H. Hahn, Enhanced specific grain boundary conductivity in nanocrystalline $\mathrm{Y}_{2} \mathrm{O}_{3}$-stabilized zirconia, Solid State Ionics, 1999, vol. 118, no. 3-4, pp. 331-339. https://doi.org/10.1016/s01672738(98)00452-4

[19] X. Guo and R. Waser, Electrical properties of the grain boundaries of oxygen ion conductors: Acceptor-doped zirconia and ceria, Progress in Materials Science, 2006, vol. 51, no. 2, pp. 151210. https://doi.org/10.1016/j.pmatsci.2005.07.001

[20] V. Singh, S. Babu, A. S. Karakoti, A. Agarwal and S. Seal, Effect of Submicron Grains on Ionic Conductivity of Nanocrystalline Doped Ceria, J. Nanosci. Nanotechnol., 2010, vol. 10, pp. 1-9. https://doi.org/10.1166/jnn.2010.2523

[21] S. P. S. Badwal, Grain boundary resistivity in zirconia-based materials: effect of sintering temperatures and impurities, Solid State Ionics, 1995, vol. 76, no. 1-2, pp. 67-80. https://doi.org/ 10.1016/0167-2738(94)00236-L
[22] J. M. Ralph, J. A. Kilner and B. C. H. Steele, Improving gd-doped ceria electrolytes for low temperature solid oxide fuel cells, Mater. Res. Soc. Symp. - Proc., 1999, vol. 575, pp. 309-314. https://doi.org/10.1557/proc-575-309

[23] X. Guo, Effect of $\mathrm{Nb}_{2} \mathrm{O}_{5}$ on the space-charge conduction of $\mathrm{Y}_{2} \mathrm{O}_{3}$-stabilized $\mathrm{ZrO}_{2}$, Solid State Ionics, 1997, vol. 99, no. 1-2, pp. 137-142. https://doi.org/10.1016/s0167-2738(97)00147-1

[24] X. Guo, Space-charge conduction in yttria and alumina codoped-zirconia, Solid State Ionics, 1997, vol. 96, no. 3-4, pp. 247-254. https://doi.org/10.1016/s0167-2738(96)00593-0

[25] J.-H. Lee, T. Mori, J.-G. Li, T. Ikegami, M. Komatsu and H. Haneda, Improvement of Grain-Boundary Conductivity of $8 \mathrm{~mol} \%$ Yttria-Stabilized Zirconia by Precursor Scavenging of Siliceous Phase, J. Electrochem. Soc., 2000, vol. 147, no. 7, pp. 2822-2829. https://doi.org/10.1149/1.1393612

[26] Hannes C. Schniepp, Je-Luen Li, Michael J. McAllister, Hiroaki Sai, Margarita HerreraAlonso, Douglas H. Adamson, Robert K. Prud'homme, Roberto Car, Dudley A. Saville, and Ilhan A. Aksayhttps, Functionalized single graphene sheets derived from splitting graphite oxide, J. Phys. Chem. B, 2006, vol. 110, no. 17, pp. 8535-8539. https://doi.org/10.1021/jp060936f

[27] S. Pei and H. M. Cheng, The reduction of graphene oxide, Carbon, 2012, vol. 50, no. 9, pp. 3210-3228. https://doi.org/10.1016/ j.carbon.2011.11.010

[28] J. Chen, B. Yao, C. Li and G. Shi, An improved Hummers method for eco-friendly synthesis of graphene oxide, Carbon, 2013, vol. 64, pp. 225-229. https://doi.org/10.1016/ j.carbon.2013.07.055

[29] Sasha Stankovich, Dmitriy A. Dikin, Richard D. Piner, Kevin A.Kohlhaas, Alfred Kleinhammes, Yuanyuan Jia, Yue Wu, Son Binh T. Nguyen and Rodney S.Ruoff, Synthesis of graphene-based nanosheets via chemical reduction of exfoliated graphite oxide, Carbon, 2007, vol. 45, no. 7, pp. 1558-1565. https://doi.org/10.1016/ j.carbon.2007.02.034

[30] Dongxing Yang, ArunaVelamakanni, Gülay Bozoklu, Sungjin Park, Meryl Stoller, Richard D. Piner, Sasha Stankovich, Inhwa Jung, Daniel A. Field, Carl A. Ventrice Jr. and Rodney S.Ruoff, Chemical analysis of graphene oxide films after heat and chemical treatments by $X$-ray photoelectron and Micro-Raman spectroscopy, Carbon, 2009, vol. 47, no. 1, pp. 145-152. https://doi.org/10.1016/j.carbon.2008.09.045 
[31] M. J. Fernández-Merino, L. Guardia, J. I. Paredes, S. Villar-Rodil, P. Solís-Fernández, A. MartínezAlonso and J. M. D. Tascón, Vitamin C is an ideal substitute for hydrazine in the reduction of graphene oxide suspensions, J. Phys. Chem. C, 2010, vol. 114, no. 14, pp. 6426-6432. https://doi.org/10.1021/jp100603h

[32] Hyeon Jin Shin, Ki Kang Kim, Anass Benayad, Seon Mi Yoon, Hyeon Ki Park, In Sun Jung, Mei Hua Jin, Hae Kyung Jeong, Jong Min Kim, Jae Young Choi and Young Hee Lee, Efficient Reduction of Graphite Oxide by Sodium Borohydride and Its Effect on Electrical Conductance, Adv. Funct. Mater., 2009, vol. 19, no. 12,pp. 1987-1992. https://doi.org/10.1002/ adfm.200900167

[33] R. S. Dey, S. Hajra, R. K. Sahu, C. R. Raj and M. K. Panigrahi, A rapid room temperature chemical route for the synthesis of graphene: Metalmediated reduction of graphene oxide, Chem. Commun., 2012, vol. 48, no. 12, pp. 1787-1789. https://doi.org/10.1039/c2cc16031e

[34] W. Gao, L. B. Alemany, L. Ci and P. M. Ajayan, New insights into the structure and reduction of graphite oxide, Nat. Chem., 2009, vol. 1, no. 5, pp. 403-408. https://doi.org/10.1038/nchem.281

[35] J. N. Ding, Y. B. Liu, N. Y. Yuan, G. Q. Ding, Y. Fan and $\mathrm{C} . \mathrm{T}$. Yu, The influence of temperature, time and concentration on the dispersion of reduced graphene oxide prepared by hydrothermal reduction, Diam. Relat. Mater., 2012, vol. 21, pp. 11-15. https://doi.org/10.1016/ j.diamond.2011.08.004

[36] H. A. Becerril, J. Mao, Z. Liu, R. M. Stoltenberg, Z. Bao and Y. Chen, Evaluation of solutionprocessed reduced graphene oxide films as transparent conductors, ACS Nano, 2008, vol. 2, no. 3, pp. 463-470. https://doi.org/10.1021/ nn700375n

[37] X. Wang, L. Zhi and K. Müllen, Transparent, conductive graphene electrodes for dyesensitized solar cells, Nano Lett., 2008, vol. 8, no. 1, pp. 323-327. https://doi.org/10.1021/n1072838r

[38] X. Xie, Y. Zhou and K. Huang, Advances in Microwave-Assisted Production of Reduced Graphene Oxide, Front. Chem., 2019, vol. 7, art. 00355. https://doi.org/10.3389/fchem.2019.00355

[39] P. Miranzo, M. Belmonte and M. I. Osendi, From bulk to cellular structures: A review on ceramicl graphene filler composites, J. Eur. Ceram. Soc., 2017, vol. 37, no. 12, pp. 3649-3672.

https://doi.org/10.1016/j.jeurceramsoc.2017.03.016

[40] A. Nieto, A. Bisht, D. Lahiri, C. Zhang and A. Agarwal, Graphene reinforced metal and ceramic matrix composites: a review, International Materials Reviews, 2017, vol. 62, no. 5, pp. 241-302. https://doi.org/10.1080/ 09506608.2016.1219481

[41] L. S. Walker, V. R. Marotto, M. A. Rafiee, N. Koratkar and E. L. Corral, Toughening in graphene ceramic composites, ACS Nano, 2011, vol. 5, no. 4, pp. 3182-3190. https://doi.org/ $10.1021 / \mathrm{nn} 200319 \mathrm{~d}$

[42] H. Porwal, P. Tatarko, S. Grasso, J. Khaliq, I. Dlouhý and M. J. Reece, Graphene reinforced alumina nano-composites, Carbon, 2013, vol. 64, pp. 359-369. https://doi.org/10.1016/ j.carbon.2013.07.086

[43] C. Ramirez, L. Garzón, P. Miranzo, M. I. Osendi and C. Ocal, Electrical conductivity maps in graphene nanoplatelet/silicon nitride composites using conducting scanning force microscopy, Carbon, 2011, vol. 49, no. 12, pp. 3873-3880. https://doi.org/10.1016/ j.carbon.2011.05.025

[44] Jian Liu, Yang Yang, Hany Hassanin, Neeraj Jumbu, Sunan Deng, Qian Zuo and Kyle Jiang, Graphene-Alumina Nanocomposites with Improved Mechanical Properties for Biomedical Applications, ACS Appl. Mater. Interfaces, vol. 8, no. 4, pp. 2607-2616. https://doi.org/10.1021/ acsami.5b10424

[45] Harshit Porwal, Peter Tatarko, Salvatore Grasso, Chunfeng Hu, Aldo R. Boccaccini, Ivo Dlouhý and Mike J. Reece, Toughened and machinable glass matrix composites reinforced with graphene and graphene-oxide nano platelets, Sci. Technol. Adv. Mater., 20136, vol. 14, no. 5. https://doi.org/10.1088/1468-6996/14/5/055007

[46] Yuchi Fan, Lianjun Wang, Jianlin Li, Jiaqi Li, Shikuan Sun, Feng Chen, Lidong Chen and Wan Jiang, Preparation and electrical properties of graphene nanosheet/ $\mathrm{Al}_{2} \mathrm{O}_{3}$ composites, Carbon, vol. 48, no. 6, pp. 1743-1749. https://doi.org/ 10.1016/j.carbon.2010.01.017

[47] P. Kun, O. Tapasztó, F. Wéber and C. Balázsi, Determination of structural and mechanical properties of multilayer graphene added silicon nitride-based composites, Ceram. Int., 2012, vol. 38, no. 1, pp. 211-216. https://doi.org/10.1016/ j.ceramint.2011.06.051

[48] J. I. Paredes, S. Villar-Rodil, A. Martínez-Alonso and J. M. D. Tascón, Graphene oxide dispersions in organic solvents, Langmuir, vol. 24, no. 19, pp. 10560-10564. https://doi.org/10.1021/la801744a

[49] Y. Hernandez et al., High-yield production of graphene by liquid-phase exfoliation of 
graphite, Nat. Nanotechnol., 2008, vol. 3, no. 9, pp. 563-568. https://doi.org/10.1038/ nnano. 2008.215

[50] B. Lee, M. Y. Koo, S. H. Jin, K. T. Kim and S. H. Hong, Simultaneous strengthening and toughening of reduced graphene oxidelalumina composites fabricated by molecular-level mixing process, Carbon, 2014, vol. 78, pp. 212-219. https://doi.org/10.1016/j.carbon.2014.06.074

[51] X. Yu, J. Xu, H. Lu and G. Fang, Sol-gel derived Al-doped zinc oxide - Reduced graphene oxide nanocomposite thin films, J. Alloys Compd., 2017, vol. 699, pp. 79-86. https://doi.org/10.1016/ j.jallcom.2016.12.326

[52] Cristina Ramírez, Sofia M. Vega-Diaz, Aaron Morelos-Gómez, Filipe M.Figueiredo, Mauricio Terrones, Maria Isabel Osendi, Manuel Belmonte and Pilar Miranzo, Synthesis of conducting graphene/Si3N4 composites by spark plasma sintering, Carbon, 2013, vol. 57, pp. 425-432. https://doi.org/10.1016/j.carbon.2013.02.015

[53] T. Ukai, Tohru Sekino, Ari T. Hirvonen, Norihito Tanaka, Takafumi Kusunose, Tadachika Nakayama and Koichi Niihara, Preparation and Electrical Properties of Carbon Nanotubes Dispersed Zirconia Nanocomposites, Key Eng. Mater., 2006, vol. 317-318, pp. 661-664. https://doi.org/10.4028/www.scientific.net/ KEM.317-318.661

[54] K. Markandan, J. K. Chin and M. T. T. Tan, Enhancing electroconductivity of yytriastabilised zirconia ceramic using graphene platlets, Key Eng. Mater., 2016, vol. 690, pp. 1-5. https://doi.org/10.4028/www.scientific.net/ KEM.690.1

[55] Y. Fan, L. Kang, W. Zhou, W. Jiang, L. Wang and A. Kawasaki, Control of doping by matrix in fewlayer graphenel metal oxide composites with highly enhanced electrical conductivity, Carbon, 2015, vol. 81, no. 1, pp. 83-90. https://doi.org/ 10.1016/j.carbon.2014.09.027

[56] B. Román-Manso, E. Domingues, F. M. Figueiredo, M. Belmonte and P. Miranzo, Enhanced electrical conductivity of silicon carbide ceramics by addition of graphene nanoplatelets, J. Eur. Ceram. Soc., 2015, vol. 35, no. 10,pp. 2723-2731. https://doi.org/10.1016/ j.jeurceramsoc.2015.03.044

[57] R. Poyato, J. Osuna, A. Morales-Rodríguez and Gallardo-López, Electrical conduction mechanisms in graphene nanoplatelet/yttria tetragonal zirconia composites, Ceram. Int., 2018, vol. 44, no. 12, pp. 14610-14616. https://doi.org/10.1016/j.ceramint.2018.05.082
[58] D. Marinha and M. Belmonte, Mixed-ionic and electronic conduction and stability of YSZgraphene composites, J. Eur. Ceram. Soc., 2019, vol. 39, no. 2-3, pp. 389-395. https://doi.org/ 10.1016/j.jeurceramsoc.2018.09.016

[59] Y. Fan, W. Jiang and A. Kawasaki, Highly Conductive Few-Layer Graphene/Al2O3 Nanocomposites with Tunable Charge Carrier Type, Adv. Funct. Mater., 2012, vol. 22, no. 18, pp. 3882-3889. https://doi.org/10.1002/ adfm.201200632

[60] M. Drozdova, D. Pérez-Coll, M. Aghayan, R. Ivanov, M. A. Rodríguez and I. Hussainova, Hybrid graphene/alumina nanofibers for electrodonductive zirconia, Key Eng. Mater., 2016, vol. 674, pp. 15-20. https://doi.org/10.4028/ www.scientific.net/KEM.674.15

[61] C. Ramirez, M.I. Osendi, P. Miranzo, M. Belmonte, F. Figueiredo, A. Castro-Beltrán and M. Terrones, Graphene nanoribbon ceramic composites, Carbon, 2015, vol. 90, pp. 207-214. https://doi.org/10.1016/j.carbon.2015.04.014

[62] Y. Teraoka, H. M. Zhang, K. Okamoto and $\mathrm{N}$. Yamazoe, Mixed ionic-electronic conductivity of La1-xSrxCo1-yFeyO3-Sperovskite-type oxides, Mater. Res. Bull., 1988, vol. 23, no. 1, pp. 51-58. https://doi.org/10.1016/00255408(88)90224-3

[63] J. Sunarso, S. Baumann, J.M. Serra, W.A. Meulenberg, S. Liu, Y.S. Lin and J.C. Diniz da Costa, Mixed ionic-electronic conducting (MIEC) ceramic-based membranes for oxygen separation, Journal of Membrane Science, 2008, vol. 320, no. 1-2, pp. 13-41. https://doi.org/ 10.1016/j.memsci.2008.03.074

[64] Philippe Vernoux, Leonardo Lizarraga, Mihalis N. Tsampas, Foteini M. Sapountzi, Antonio De Lucas-Consuegra, Jose-Luis Valverde, Stamatios Souentie, Costas G. Vayenas, Dimitris Tsiplakides, Stella Balomenou and Elena A. Baranova, Ionically conducting ceramics as active catalyst supports, Chemical Reviews, 2013, vol. 113, no. 10, pp. 8192-8260. https://doi.org/ $10.1021 / \mathrm{cr} 4000336$

[65] Y. Fan, L. Kang, W. Zhou, W. Jiang, L. Wang and A. Kawasaki, Control of doping by matrix in fewlayer graphenel metal oxide composites with highly enhanced electrical conductivity, Carbon, 2015, vol. 81, no. 1, pp. 83-90. https://doi.org/ 10.1016/j.carbon.2014.09.027

[66] J. P. Moore, R. S. Graves and D. L. Mcelroy, Thermal and Electrical Conductivities and Seebeck Coefficients of Unirradiated and 
Irradiated Graphites from 300 To 1000 K, Oak Ridge National Laboratory, Jan. 1973

[67] J. H. Shin and S. H. Hong, Fabrication and properties of reduced graphene oxide reinforced yttria-stabilized zirconia composite ceramics, J. Eur. Ceram. Soc., 2014, vol. 34, no. 5, pp. 1297-1302. https://doi.org/10.1016/ j.jeurceramsoc.2013.11.034

[68] Fei Chen, Dongqin Jin, Khalid Tyeb, Botao Wang, Young-Hwan Han, Sukyoung Kim, Julie M. Schoenung, Qiang Shen and Lianmeng Zhang, Field assisted sintering of graphene reinforced zirconia ceramics, Ceram. Int., 2015, vol. 41, no. 4, pp. 6113-6116. https://doi.org/10.1016/ j.ceramint.2014.12.147

[69] X. Wang, N. P. Padture and H. Tanaka, Contactdamage-resistant ceramic/single-wall carbon nanotubes and ceramic/graphite composites, Nat. Mater., 2004, vol. 3, no. 8, pp. 539-544. https://doi.org/10.1038/nmat1161

[70] J. Su, Y. Chen and Q. Huang, Graphene nanosheet-induced toughening of yttria- stabilized zirconia, Appl. Phys. A Mater. Sci. Process., 2017, vol. 123, no. 1, pp. 1-11. https://doi.org/10.1007/s00339-016-0613-7

[71] R. Cano-Crespo, B. M. Moshtaghioun, D. GómezGarcía, R. Moreno and A. Domínguez-Rodríguez, Graphene or carbon nanofiber-reinforced zirconia composites: Are they really worthwhile for structural applications?, J. Eur. Ceram. Soc., 2018, vol. 38, no. 11, pp. 3994-4002.

https://doi.org/10.1016/j.jeurceramsoc.2018.04.045

[72] S. Ramesh et al., Sintering behaviour and properties of graphene oxide-doped Y-TZP ceramics, Ceram. Int., 2016, vol. 42, no. 15, pp. 17620-17625. https://doi.org/10.1016/ j.ceramint.2016.08.077

[73] O. Y. Kurapova, A. G. Glukharev, O. V. Glumov, M. Y. Kurapov, E. V. Boltynjuk and V. G. Konakov, Structure and electrical properties of YSZ-rGO composites and YSZ ceramics, obtained from composite powder, Electrochim. Acta, 2019, vol. 320, art. 134573, 2019. https://doi.org/10.1016/ j.electacta.2019.134573 